\title{
Can MRI quantify the volume changes of denervated facial muscles?
}

\author{
Valeria Mastryukova (1, 2), Dirk Arnold (1,3), Daniel Güllmar (4), Orlando Guntinas- \\ Lichius $(1,2)$, Gerd Fabian Volk $(1,2)$
}

(1) ENT-Department, Jena University Hospital, Jena, Germany; (2) Facial Nerve Center Jena, Jena University Hospital, Jena, Germany; (3) Institute of Systematic Zoology and Evolutionary Biology with Phyletic Museum, Friedrich-Schiller-University Jena, Jena, Germany; (4) Medical Physics Group, Institute of Diagnostic and Interventional Radiology, Jena University Hospital, Jena, Germany

This article is distributed under the terms of the Creative Commons Attribution Noncommercial License (CC BY-NC 4.0) which permits any noncommercial use, distribution, and reproduction in any medium, provided the original author(s) and source are credited.

\begin{abstract}
Could manual segmentation of magnetic resonance images be used to quantify the effects of transcutaneous electrostimulation and reinnervation of denervated facial muscle? Five patients with unilateral facial paralysis were scanned during the study while receiving a daily surface electrostimulation of the paralytic cheek region, but also after reinnervation. Their facial muscles were identified in 3D (coronal, sagittal, and axial) and segmented in magnetic resonance imaging (MRI) data for in total 28 time points over the 12 months of study. A non-significant trend of increasing muscle volume were detected after reinnervation. MRI is a valuable technique in the facial paralysis research.
\end{abstract}

Key Words: Electrostimulation; facial paralysis; denervated muscle; muscle volume, MRI segmentation

Eur J Transl Myol 30 (1): 144-149, 2020

Facial expressions are fundamental to one's sense of well-being and ability to integrate into society. Impaired facial expressions due to facial paralysis potentially result in social anxiety and emotional distress, crippling the individual in daily life. ${ }^{1}$ Untreated severe facial palsy leaves patients with incomplete recovery, poor facial function and low quality of life in addition to numerous other complications. ${ }^{2}$ There are invasive and noninvasive interventions available to restore symmetry. Direct repair of the facial nerve was first reported in the year $1821 .^{3}$ Dynamic reanimation of the face can only be achieved by reanimation of functional muscle units on the affected regions of the face. In addition to those procedures designed to reanimate the facial movements, a large number of procedures exist to provide static support to the paralyzed areas. Furthermore, in cases where the facial paralysis is localized to a particular region of the face, if post-paralytic synkinesis occurs, or to supplement previous surgical attempts, contralateral chemodenervation of the healthy facial musculature is a common treatment option to improve facial symmetry. ${ }^{4,5}$ Noninvasive treatment options are an essential adjunct to the aforementioned invasive techniques. A spectrum of interventions exists with continuing debate of their effectiveness as an isolated treatment. These range from stretching exercises to electrical stimulation ${ }^{6}$ through neuromuscular retraining. The prime interest of many researchers are the significant consequences of facial nerve paralysis and new techniques that have been introduced throughout the years. ${ }^{7}$ Denervation of the muscle causes mass loss, a decrease in cross-sectional area of muscle fibers, and a decrease in muscle force production. ${ }^{8}$ Reduction of muscle atrophy of the target muscle improves the functional capacity of the muscle. On this regard, several authors suggested a beneficial effect of electrical muscle stimulation during the nerve regeneration process. ${ }^{6,9,10}$ And also, electrical stimulation is the most direct method suggested for minimizing muscle atrophy during the denervation period. Bueno et al., conducted an experiment on tibial muscles in rats showing that electrical stimulation minimized muscle atrophy in cases with chronic denervation. ${ }^{11}$ Patients with paraplegia were studied by Kern et al., in that study they used 1 year-long home-based daily FES-training on the denervated limb muscles. They recorded the increase in muscle bulk, ${ }^{8}$ and after a second year of training they studied the achievements in a small series of biopsies muscle tissue and reported myofiber size increase. So, if the FES-training serves well with limb denervated muscle, ${ }^{12}$ can we apply it to the facial musculature? Recently, we conducted a research that proves that FES 
for facial musculature is tolerable and does not delay or in any way interrupt the reinnervation process and does not contribute to the synkinesis. ${ }^{13,14}$ What we are interested in, is the use of FES training therapy in cases of complete peripheral facial paralysis and the use of MRI as a method to quantify the changes.

\section{Materials and Methods}

Approval for the study was obtained through the local institutional review board and written informed consent was obtained from all study participants. Five patients [4 females, aged 30-60 years $(\mathrm{MD}=44.2, \mathrm{SD}=12.3)]$ with complete unilateral facial paralysis were recruited to participate in the study. Needle-EMG was used to exclude any innervation of the paralyzed hemiface before including a patient into the study. ${ }^{15}$ During the study, every four weeks a facial needle-EMG was repeated to detect the reinnervation processes. Stimulette $r 2 x$ (Schuhfried, Vienna, Austria) served as a home training device. Detailed instructions were given to the patients to place two self-adhesive surface electrodes (40x60 mm Flextrode Plus; Krauth + Timmermann, Hamburg, Germany) on the skin above the zygomaticus, depressor anguli oris and depressor labii inferior muscles to be trained. Every month during the follow-up visits FES confirmation or correction and adjustments of FES training parameters were performed. All the participants kept home-training diaries. The MRI data was acquired with a Siemens Prisma 3T scanner (Siemens, Erlangen, Germany) equipped with 64-chanel head/neck coil provided by the manufacturer. Due to organisational reasons, not for every follow up visit but only around every second or third one a MRI scan was performed. The imaging protocol consisted of T1-weighted inversion recovery sequence, ${ }^{16}$ with the following sequence parameters: $\mathrm{TE}=2.07 \mathrm{~ms}, \mathrm{TR}=2300 \mathrm{~ms}, \mathrm{TI}=900 \mathrm{~ms}$, Matrix-size $=256 \times 256$ pxls, FOV=256x256 mm, slice thickness $=1 \mathrm{~mm}$, nbr. of slices $=192$, pixel bandwidth=230 Hz/pixel, flip angle=9, sagittal orientation, covering the whole head including the face. The procedure lasted approximately 10 minutes in total. The MRI procedure was explained to all of the participants by the radiologist on duty, who again screened for exclusion criteria and confirmed the absence of major pathologies according to the T1-weighted anatomical images after measurements. Patients received ear protection with earplugs. The patients were placed in the supine position with their arms on either side of their body. Manual segmentation of the facial muscles (corrugator supercilia, depressor anguli oris, oculi oris and zygomaticus) was performed and facial muscle masks were created using 3D slicer 4.10 software package (https://www.slicer.org/). After the segmentation, the mask volumes and mean gray values were available. The duration of muscle set segmentation was measured with the stopwatch. For the statistical analysis, paired t-test was conducted with IBM SPSS statistics software (Version 25; IBM, New York, USA) to compare the volume change of the denervated muscles during the FES-training but also before and after the reinnervation.

\section{Results and Discussion}

The case Patient001, a female, presented a complete unilateral facial paralysis post parotidectomy and facialnerve-suture after removal of an intraparotideal facial nerve schwannoma. She was included into the study one week after the operation. Four months after inclusion into the study and start of daily FES (Sept. 2018), the patient showed the first signs of reinnervation. As it is shown on Figure 1 (Volume change in $\%$ of the zygomaticus muscle of Pat001 over a time of 12 months.) the volume of the targeted zygomaticus muscle on the affected side increased with a delay after reinnervation. The first signs

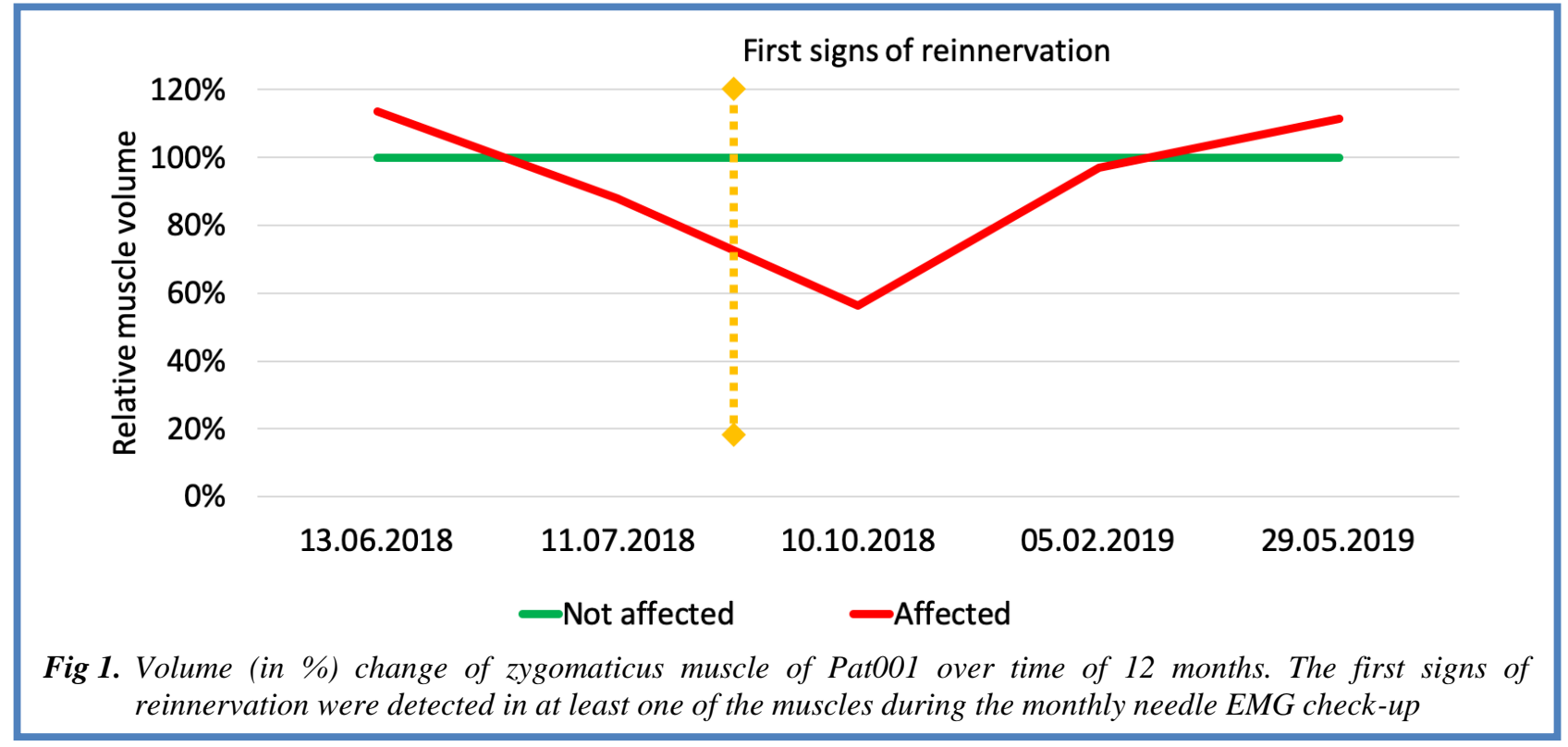




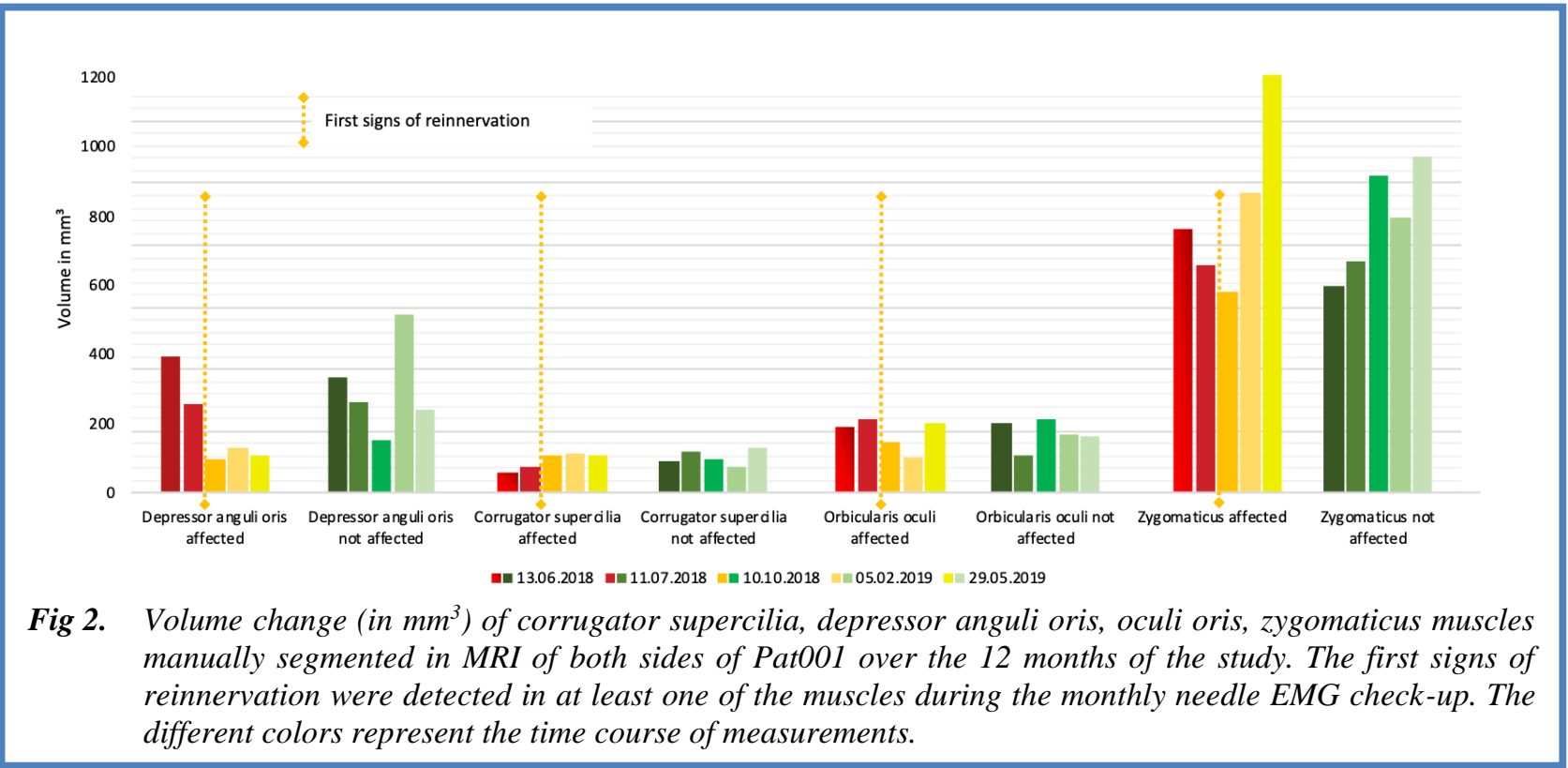

of reinnervation were detected in at least one of the muscles during the monthly needle EMG check-up. A closer look to the changes in muscle volumes invoked by the FES training and beginning of the reinnervation processes is provided in Figure 2. The beginning of the reinnervation process was defined as the time point when in any of the routinely checked muscles (frontalis, zygomaticus, orbicularis oculi and oris muscles) during the needle-EMG any voluntary muscle activity was detected. For Patient001 the reinnervation processes were detected in all the muscles except the frontalis on the September 2018 visit. The decrease of the volume went on until the next MRI scan in October 2018. The interesting part is that the beginning of the reinnervation that was detected during the third monthly visit in September 2018 did not immediately stop the atrophy processes. However, the increase of the muscle volume was observed from October 2018 (4th month) on and could be explained by the slowly ongoing process of reinnervation, when few reinnervating axons reached the denervated muscle fibers. The volume of the zygomaticus muscle on the non-affected side was



Fig 3. Volume Changes in zygomaticus muscle over the training-and reinnervation-time for the five patients of the study. The mean distance between two columns is 71 days (min: 21 days, max: 239 days). The first signs of reinnervation were detected in at least one of the muscles during the monthly needle EMG check-up. 
Table 1. Volumes of zygomaticus muscles in the four of the five patients in which reinnervation process started.

\begin{tabular}{|c|c|c|c|c|}
\hline & $\begin{array}{c}\text { Last MRI before } \\
\text { reinnervation }\end{array}$ & $\begin{array}{c}\text { Date } \\
\text { pumber of months into } \\
\text { the study) }\end{array}$ & st MRI after the reinnervation & $\begin{array}{c}\text { Date } \\
\text { pumber of months into the study) }\end{array}$ \\
\hline pat001 & $578 \mathrm{~mm}^{3}$ & $\begin{array}{c}10.10 .2018 \\
4 \text { months }\end{array}$ & $1208 \mathrm{~mm}^{3}$ & $\begin{array}{c}05.02 .2019 \\
8 \text { months }\end{array}$ \\
\hline pat002 & $667 \mathrm{~mm}^{3}$ & $\begin{array}{c}18.07 .2018 \\
1 \text { month }\end{array}$ & $473 \mathrm{~mm}^{3}$ & $\begin{array}{c}06.11 .2018 \\
5 \text { months }\end{array}$ \\
\hline pat003 & N/A & $\begin{array}{c}14.08 .2018 \\
\text { Nonth }\end{array}$ & $814 \mathrm{~mm}^{3}$ & $\begin{array}{c}\text { N/A } \\
12 \text { months }\end{array}$ \\
\hline pat004 & $533 \mathrm{~mm}^{3}$ & $\begin{array}{c}10.10 .2018 \\
3 \text { months }\end{array}$ & $663 \mathrm{~mm}^{3}$ & $\begin{array}{c}19.02 .2019 \\
7 \text { months }\end{array}$ \\
\hline pat005 & $803 \mathrm{~mm}^{3}$ & & $\mathrm{M}=789.5, \mathrm{SD}=311.94$ \\
\hline M, SD & \multicolumn{2}{|c|}{$\mathrm{M}=687.5, \mathrm{SD}=93.03$} & & \\
\hline
\end{tabular}

increased during the FES-training even before the first signs of reinnervation and plateaued after the electrostimulation stopped, 2 months after the first signs of the reinnervation. That was possible because a contraction of the zygomaticus muscle on the paretic side of the face induced a stretch of the zygomaticus muscle of the opposite side of the face17. In addition, we saw the initial decrease and post-reinnervation increase in both zygomaticus and depressor anguli oris muscle. Early corrugator muscle volume change could be explained by the reinnervation from the healthy side over the midline. The changes in orbicularis oculi volume are not easy to interpret neither by the reinnervation nor by the FEStraining effects. However, the result for the zygomaticus muscle looked promising so we explore the changes for all five patients. On Figure 3 the results of zygomaticus muscle segmentation for all five patients are presented. The muscle volume changes showed a high variability, especially in the not affected side, but nonetheless some showed interesting trends as in the case of Patient002. The patient started FES-training 1 month after denervation. During the first month of FES-training the volume of the zygomaticus increased, but in the next period between the second and third MRI measurements for the last 66 (out of 111) days patient paused FEStraining due to skin condition (minor skin irritation on the area where electrodes were placed, not related to FES) and a substantial decrease in the volume was registered. We assume that it could be because denervated muscles, without FES, lose volume due to denervation atrophy. Patient003 has an ongoing denervation since 2002 and no signs of the reinnervation had been detected. The overall increase trend of the affected side zygomaticus muscle volume could be evoked by the FES-training but the volume decrease on the non-affected side is hard to interpret. We expect that reinnervation has the strongest effect on the muscle volume - the muscle should start growing again. For the further analysis, Patient003 was excluded because no reinnervation occurred during the period of the study. We could see the increase in muscle volume after the reinnervation not only in Patient001, but also in Patient004 and Patient005 (Table1). However, these changes are not statistically significant when comparing the zygomaticus muscle volumes in the last MRI before the reinnervation $(\mathrm{M}=645.25, \mathrm{SD}=119)$ and last MRI after the reinnervation $(\mathrm{M}=789.5, \mathrm{SD}=$ 311.94); $\mathrm{t}(3)=0.75, \mathrm{p}=0.510)$.

\section{Limitations}

Small sample size is a big limitation; therefore, a limited statistical analysis was conducted. Method of manual MRI segmentation adds to the limitations. Segmentation of large MRI volumes is a major time-consuming task. The average time required for one muscle-set (both sides) segmentation was 40 60 min depending on the muscle. Moreover, manual segmentation using the three orthogonal views may result in uneven boundaries, which causes difficulties in object analysis as well as the partial volume effect (PVE) occurs and complicates the segmentation process. In other words, in the imaging methods several anatomical entities contribute to the gray-level intensity of a single pixel/voxel. Segmentation in the non-homogeneous areas with limited resolution of the scanning hardware and the discretization procedures, results in blurred intensities across edges. This makes the task of accurately delineate the borders between two connected objects difficult ${ }^{18}$. Instead of trying to segment the muscles in the classical anatomical definitions, using regions of interests or groups of related muscles together could make the task easier.

\section{Conclusion}

Can MRI quantify the effect of electrostimulation along with denervation and reinnervation? We find MRI segmentation a promising technique for facial paralysis research ${ }^{19}$ and specifically muscle assessment. ${ }^{20}$ Unlike the ultrasound, the other imaging method frequently used in the facial palsy research, MRI captures the whole muscle and not just a section. On an individual level or for studies with only a small sample size, the poor signalto-noise ratio of the method is a limitation. We propose automatization of facial muscles segmentation, i.e., a semi-automatic approach that would achieve a process standardization and that will reduce the time required for segmentation. ${ }^{21}$ 


\section{List of acronyms}

MRI - Magnetic resonance imaging

FES - Functional electrical stimulation

EMG - electromyogram

\section{Authors contributions}

GFV developed the study design. He and OG-L have contributed to the finalizing the manuscript, DA participated in data acquisition, DG contributed to the data analysis, VM participated in data acquisition, analyses of data and in drafting and finalizing the manuscript.

\section{Acknowledgments}

The authors thank colleagues of the Facial-Nerve-Center Jena for discussions and critical readings.

\section{Funding}

MED-EL, Innsbruck, Austria; German Research Foundation (Deutsche Forschungsgemeinschaft; DFG): GU 463/12-1; DEGUM

\section{Conflict of Interest}

The authors declare they have no financial, personal, or other conflicts of interest.

\section{Ethical Publication Statement}

We confirm that we have read the Journal's position on issues involved in ethical publication and affirm that this report is consistent with those guidelines.

\section{Corresponding Author}

Gerd Fabian Volk, ENT-Department and Facial Nerve Center Jena, Jena University Hospital, Am Klinikum 1, 07747 Jena, Germany.

ORCID iD: 0000-0003-1245-6331

E-mail: Fabian.Volk@med.uni-jena.de

\section{E-mails of co-authors}

Valeria Mastryukova: valeria.mastryukova@med.uni-jena.de

ORCID iD: 000-0003-4461-1412

Dirk Arnold: d.arnold@uni-jena.de

ORCID iD: 0000-0001-8089-3934

Daniel Güllmar: daniel.guellmar@med.uni-jena.de ORCID iD: 0000-0001-8693-8099

Orlando Guntinas-Lichius: orlando.guntinas@med.uni-jena.de ORCID iD: 0000-0001-9671-0784

\section{References}

1. Stuart RM, Byrne PJ. The importance of facial expression and the management of facial nerve injury. Neurosurg Q 2004. doi:10.1097/00013414200412000-00009

2. Coulson SE, O'dwyer NJ, Adams RD, Croxson GR. Expression of emotion and quality of life after facial nerve paralysis. Otol Neurotol Off Publ Am Otol Soc Am Neurotol Soc [and] Eur Acad Otol
Neurotol 2004;25:1014-9. doi:10.1097/00129492200411000-00026

3. Butler DP, Grobbelaar AO. Facial palsy: what can the multidisciplinary team do? J Multidiscip Healthc 2017;10:377-81. doi:10.2147/JMDH.S 125574

4. Harrison DH, Grobbelaar AO. Pectoralis minor muscle transfer for unilateral facial palsy reanimation: An experience of 35 years and 637 cases. J Plast Reconstr Aesthetic Surg 2012;65:84550. doi:10.1016/j.bjps.2012.01.024

5. Guntinas-Lichius O, Glowka TR, Angelov DN, et al. Improved functional recovery after facial nerve reconstruction by temporary denervation of the contralateral mimic musculature with botulinum toxin in rats. Neurorehabil Neural Repair 2011;25(1):15-23. doi:10.1177/15459683103760 58

6. Targan RS, Alon G, Kay SL. Effect of long-term electrical stimulation on motor recovery and improvement of clinical residuals in patients with unresolved facial nerve palsy. Otolaryngol Head Neck Surg 2000;122:246-52. doi:10.1016/S01945998(00)70248-8

7. Teixeira LJ, Valbuza JS, Prado GF. Physical therapy for Bell's palsy (idiopathic facial paralysis). Cochrane database Syst Rev. 2011;(12):CD006283. doi:10.1002/14651858.CD006283.pub3

8. Kern H, Carraro U, Adami N, et al. One year of home-based daily FES in complete ower motor neuron paraplegia: Recovery of etanic contractility drives the structural mprovements of denervated muscle. Neurol Res 2010;32:5-12. doi:10.1179/ 174313209X385644

9. Willand MP. Electrical Stimulation Enhances Reinnervation After Nerve Injury. Eur J Transl Myol 2015;25:243-8. doi:10.4081/ejtm.2015.5243

10. Shapira Y, Sammons V, Forden J, et al. Brief Electrical Stimulation Promotes Nerve Regeneration Following Experimental InContinuity Nerve Injury. Neurosurgery 2018;85:156-63. doi:10.1093/neuros/nyy221

11. Bueno CR de S, Pereira M, Favaretto IAJ, et al. Electrical stimulation attenuates morphological alterations and prevents atrophy of the denervated cranial tibial muscle. Einstein (Sao Paulo). 2017;15:71-6. doi:10.1590/S1679-45082017AO 3808

12. Kern H, Gargiulo P, Pond A, et al. To Reverse Atrophy of Human Muscles in Complete SCI Lower Motor Neuron Denervation by Home-Based Functional Electrical Stimulation. Adv Exp Med Biol 2018;1088:585-591. doi:10.1007/978-981-131435-3 27

13. Puls WC, Jarvis JC, Ruck A, et al. Surface electrical stimulation for facial paralysis is not harmful. Muscle Nerve. 2020;61:347-353. doi:10.1002/mus .26784 


\section{MRI of denervated facial muscles}

Eur J Transl Myol 30 (1): 144-149, 2020

14. Volk GF, Thielker J, Moller MC, et al. Tolerability of facial electrostimulation in healthy adults and patients with facial synkinesis. Eur Arch Otorhinolaryngol January 2020. doi:10.1007/ s00405-020-05818-x

15. Grosheva M, Guntinas-Lichius O. Significance of electromyography to predict and evaluate facial function outcome after acute peripheral facial palsy. Eur Arch Otorhinolaryngol 2007;264:14915. doi:10.1007/s00405-007-0376-z

16. Mugler III JP, Brookeman JR. Rapid threedimensional T1-weighted MR imaging with the MP-RAGE sequence. J Magn Reson Imaging 1991;1:561-7. doi:10.1002/jmri.1880010509

17. Song $\mathrm{Y}$, Forsgren $\mathrm{S}, \mathrm{Yu} \mathrm{J}$, et al. Effects on contralateral muscles after unilateral electrical muscle stimulation and exercise. PLoS One 2012;7(12):e52230-e52230. doi:10.1371/journal. pone. 0052230

18. Engelke K, Museyko O, Wang L, Laredo J-D. Quantitative analysis of skeletal muscle by computed tomography imaging-State of the art. J Orthop Transl 2018;15:91-103. doi:10.1016/j.jot. 2018.10.004

19. Burmeister H, Baltzer P, Volk G, et al. Evaluation of the early phase of Bell's palsy using 3 T MRI. Eur Arch Otorhinolaryngol 2011;268:1493-1500. doi:10.1007/s00405-011-1498-x

20. Volk GF, Karamyan I, Klingner CM, et al. Quantitative magnetic resonance imaging volumetry of facial muscles in healthy patients with facial palsy. Plast Reconstr surgery Glob open. 2014;2(6):e173. doi:10.1097/GOX.0000000000 000128

21. Gargiulo P, Klingner C, Fridgeirsson E, et al. Side differences in MRI-scans in facial palsy: 3-D modeling, segmentation and gray value analysis. 23rd Eur Model Simul Symp EMSS 2011. January 2011:87-92.

Submitted: February 25, 2019 Accepted for publication: March 4, 2019 